\title{
Ultra-low permittivity ULTCC composite materials
}

Mikko Nelo*, Timo Vahera, Tuomo Siponkoski, Jari Juuti and Heli Jantunen

Microelectronics Research Unit, P. O. Box 4500, FI-90014, University of Oulu, Finland

* Corresponding author. Email: mikko.nelo@oulu.fi

\section{Abstract}

A method to realize ultra-low temperature co-fireable ceramic composites with ultra-low permittivity is presented in this work. Hollow glass microspheres with size of 10-100 $\mu \mathrm{m}$ were used as a filler in a tape based on lithium molybdate $\left(\mathrm{Li}_{2} \mathrm{MoO}_{4}\right)$ ceramic to introduce controlled porosity and reduce the relative permittivity of the sintered product. A lamination pressure of only 1.25 MPa was sufficient to produce samples with uniform structure and without delamination. Differential scanning calorimetry and thermogravimetric analysis were used to optimize the sintering temperature profile of the material. The microstructure of the samples was investigated with FESEM and the dielectric properties with a split post dielectric resonator (SPDR). Compatibility of the composite ceramic with silver was tested by applying thick film printed electrodes and post-firing them on the surface. Samples sintered at $540{ }^{\circ} \mathrm{C}$ exhibited a relative permittivity of $1.4-5.40$ and a loss tangent of $10^{-3}-10^{-4}$ at 5 and $10 \mathrm{GHz}$. The method shows interesting possibilities to significantly reduce processing temperatures compared to conventional LTCC materials and to obtain the extremely low permittivity that is especially required for future high frequency applications.

The high frequencies used in modern telecommunications such as $5 G$ and beyond will be sensitive to losses in signal pathway due to absorption by surrounding materials. Furthermore, very low permittivity is also required to enable fast signal propagation and to provide a counter effect for the shrinking size of the components due to the increased frequencies. A common solution to decrease permittivity is to introduce porosity into the materials, which can be done for organic [1] as well as for inorganic [2] substrates. 
Porosity has been added to organic materials, for example by utilizing foaming agents [3], the partial decomposition of material [4] or by utilizing hollow glass microspheres [5-7]. Hollow glass microspheres (HGMS) offer an inexpensive solution to increase porosity, thereby reducing dielectric permittivity and losses, while better maintaining mechanical rigidity compared to purely gas filled composites. However, although organic materials offer excellent electrical properties for substrates, their thermal stability can become an issue as power densities of future devices increase.

Ceramic composite materials, on the other hand, offer good thermal stability at higher temperatures. The downside of using ceramic materials has been their high manufacturing temperature resulting in high energy consumption and increased production costs. Ceramic materials or their glass composites have been developed to be utilized as low temperature co-fired ceramics (LTCC) sintered typically at $800-1000{ }^{\circ} \mathrm{C}[8,9]$. For HGMS these temperatures are still too high (melting temperatures at $700-850^{\circ} \mathrm{C}$ ) and therefore polymer microspheres or etching have been previously utilized to generate porosity in the ceramic [10-13]. A low relative permittivity of 3.8 for LTCC has been obtained by Xi et al. [14]. To further decrease the fabrication temperatures of the ceramics ultra-low temperature cofired ceramics (ULTCC) have been developed [15-18] that also enable the use of HGMS as presented in this paper.

With the recent invention of a room temperature fabrication method (RTF), a water-based suspension of lithium molybdenum oxide (LMO) has been used to produce bulk dielectric samples and composites [19-21]. In previous research, [2] extremely low $\varepsilon_{\mathrm{r}}$ ceramic based composite materials were produced at room temperature utilizing water suspension of LMO, HGMS and quartz fibers. This research showed very good wetting of HGMS with the LMO solution. LMO has been earlier reported [22] to have a relatively low sintering temperature of $540{ }^{\circ} \mathrm{C}$ with bulk density, relative permittivity and Qxf of $2.895 \mathrm{~g} / \mathrm{cm}^{3}(95.5 \%), 5.5$ and 46000 $\mathrm{GHz}(13.051 \mathrm{GHz})$, respectively. In addition, despite the fact that Mo being transition metal, no extra phases are likely to form as a result of changes in oxidation levels of Mo in such low temperature and ambient sintering atmosphere, which would affect the dielectric properties. [22-24] This indicates that the combination of LMO and HGMS would also offer an opportunity to fabricate multilayer structures through 
ULTCC and tape casting technologies with extremely low $\varepsilon_{r}$ and losses for high frequency applications. In this work, a slurry system for the LMO-HGMS composite for tape casting was further developed from earlier work [25] and the lamination and sintering of several layers was optimized. The high frequency properties of the composites as a function of HGMS content was studied as well as the achieved microstructures and densities.

The $\mathrm{Li}_{2} \mathrm{MoO}_{4}$ (LMO) (>99 \%; Alfa Aesar, USA) powder was milled in ethanol according to the procedure reported earlier by Väätäjä et al. [21] with $\mathrm{ZrO}_{2}$ milling media in a planetary ball mill (Pulverisette 6, Fritsch, Idar- Oberstein, Germany) to reduce the particle size and to achieve a suitable size distribution. The dried powder was sieved through a mesh size of $45 \mu \mathrm{m}$. The HGMSs (Kevra Oy, Finland) were C-type glass with 50$75 \%$ of $\mathrm{SiO}_{2}$, average sphere size of $40-80 \mu \mathrm{m}$, volumetric density of $0.1-0.15 \mathrm{~g} / \mathrm{cm}^{3}$, bulk density of $0.2 \mathrm{~g} / \mathrm{cm}^{3}$, and temperature resistance of up to $650^{\circ} \mathrm{C}$ according to the datasheet from the manufacturer. According to the SEM-EDS analysis carried out in earlier work [2], the composition of the HGMS was 72 wt.\% of $\mathrm{SiO}_{2}, 14$ wt.\% of $\mathrm{Na}_{2} \mathrm{O}$ and $14 \mathrm{wt} . \%$ of $\mathrm{CaO}$. The solvent used in the tape casting slurry was dimethyl carbonate (DMC) (>99\%, Sigma-Aldrich, USA), the binder was QPAC $^{\circledR} 40$ - PPC - poly(propylene carbonate) (Empower Materials, Inc, USA) and the plasticizers were Santicizer S160 butyl benzyl phthalate and UCON50HB2000 polyalkylene glycol (Tape Casting Warehouse, Inc, USA).

Tape casting slurries with a designed HGMS content of 0-85 vol.\% in the resulting sintered tapes were made. The organic components were first dissolved in DMC and after addition of LMO the solution was milled with zirconium oxide balls for 24 hours at a slow speed to thoroughly mix the components and deagglomerate the LMO particles. After milling, the HGMS powder was mixed in with the solution, followed by slow agitation without the milling media to remove the air bubbles from the slurry. The slurries were tape-cast through a $800 \mu \mathrm{m}$ slit on mylar film and dried under a lid at room temperature to achieve green tapes with a thickness of $200 \mu \mathrm{m}$. The compositions of different slurries are shown in Table 1. 
Table 1: Composition of the tape casting slurries.

\begin{tabular}{ccccccc}
\hline $\begin{array}{c}\text { Vol. \% of HGMS } \\
\text { in sintered tape }\end{array}$ & $\begin{array}{c}\text { HGMS } \\
{[\mathrm{g}]}\end{array}$ & $\begin{array}{c}\text { LMO } \\
{[\mathrm{g}]}\end{array}$ & $\begin{array}{c}\text { QPAC 40 } \\
{[\mathrm{g}]}\end{array}$ & $\begin{array}{c}\text { Santicizer } \\
\text { S160 } \\
{[\mathrm{g}]}\end{array}$ & $\begin{array}{c}\text { Polyalkylene } \\
\text { glycol } \\
{[\mathrm{g}]}\end{array}$ & $\begin{array}{c}\text { DMC } \\
{[\mathrm{g}]}\end{array}$ \\
\hline $0 \% \mathrm{HGMS}$ & 0 & 28 & 3.6 & 0.9 & 0.9 & 28 \\
$25 \% \mathrm{HGMS}$ & 0.5 & 21 & 3.1 & 0.75 & 0.75 & 28 \\
$50 \% \mathrm{HGMS}$ & 1.0 & 14 & 3.3 & 0.8 & 0.8 & 28 \\
$75 \% \mathrm{HGMS}$ & 1.5 & 7.0 & 3.5 & 0.9 & 0.9 & 28 \\
$85 \% \mathrm{HGMS}$ & 1.7 & 4.2 & 3.6 & 0.9 & 0.9 & 28 \\
\hline
\end{tabular}

Decomposition of organic additives and optimization of the sintering profile was studied using DSC-TGA (Netzsch STA 449 F3 Jupiter, NETZSCH-Gerätebau GmbH, Germany). The measurements were carried out in a constant gas flow of $20 \mathrm{ml} / \mathrm{min}$ in synthetic air and nitrogen (protective purge) with various temperature profiles. The temperature profile tested with DSC-TGA consisted of five segments: heating to $180{ }^{\circ} \mathrm{C}$ (3.6 $\left.{ }^{\circ} \mathrm{C} / \mathrm{min}\right)$, heating to $350^{\circ} \mathrm{C}\left(0.7^{\circ} \mathrm{C} / \mathrm{min}\right)$, heating to $540{ }^{\circ} \mathrm{C}\left(3.2^{\circ} \mathrm{C} / \mathrm{min}\right)$, hold at $540{ }^{\circ} \mathrm{C}(30 \mathrm{~min})$, cooling to 30 ${ }^{\circ} \mathrm{C}\left(3^{\circ} \mathrm{C} / \mathrm{min}\right)$. The sample size in the DCS-TGA measurement varied between 8 and $18 \mathrm{mg}$

The green tapes were cut to $40 \times 40 \mathrm{~mm}^{2}$ squares and 5-6 layers were stacked and laminated in a uniaxial press with heated plates between silicone sheets to distribute the pressure evenly. The used lamination pressure was $1.25 \mathrm{MPa}$, temperature $80^{\circ} \mathrm{C}$ and pressing time 15 minutes. The green density of the laminates was determined through their weight and dimensions. The final sintering profile was as follows: $40 \mathrm{~min}$ heating from RT to $140{ }^{\circ} \mathrm{C}, 10 \mathrm{~min}$ hold, $5 \mathrm{~h}$ heating to $260^{\circ} \mathrm{C}, 15 \mathrm{~min}$ hold, followed by $1 \mathrm{~h}$ heating to $540{ }^{\circ} \mathrm{C}$, $2 \mathrm{~h}$ hold. Sintering was finished with $8 \mathrm{~h}$ cooling to RT. A long burn out time was used to prevent the formation of gas bubbles in the laminates. A $6.0 \mathrm{~g}$ alumina sheet was placed on top of each laminate during the sintering to prevent warping. Weights and dimensions were re-measured after sintering.

Dielectric measurements were carried out with a vector network analyzer (VNA) (Rhodes \& Schwarz ZVB20, Germany) connected with a SPDR (QWED, Poland) with nominal resonances at 5.180 and $9.975 \mathrm{GHz}$. The relative permittivity and dielectric losses were calculated from measurements using QWED software. After the measurements, conductive silver lines were stencil printed on top of the samples using ESL 599-E (ElectroScience Laboratories, Inc, USA) low temperature silver paste, which was fired at $450{ }^{\circ} \mathrm{C}$ following the manufacturer's instructions. Finally, the cross-sections of the sintered samples were investigated with field 
emission scanning electron microscopy (FESEM, Carl Zeiss Ultra Plus, Germany). The samples for FESEM analysis were laser-cut and finished with ion polishing (Jeol IB-19520CCP, Jeol Ltd., Japan).

The decomposition of the organic additives in the DSC measurement is shown in Figure 1 . The onset of the first exothermic peak in the DSC data started around $150{ }^{\circ} \mathrm{C}$ and between 150 to $180^{\circ} \mathrm{C}$ the organics started to burn out from the green tape, which was also detected as a small decline in the TG curve due to mass loss. The largest mass loss and sharp exothermic peaks were seen around $190-200{ }^{\circ} \mathrm{C}$. The heating was considerably slowed in this region to prevent the formation of gas bubbles in the final product. After about $250{ }^{\circ} \mathrm{C}$ the organic additives had decomposed and no further mass loss or reactions were detected. These results are well in line with measurements reported earlier [25].

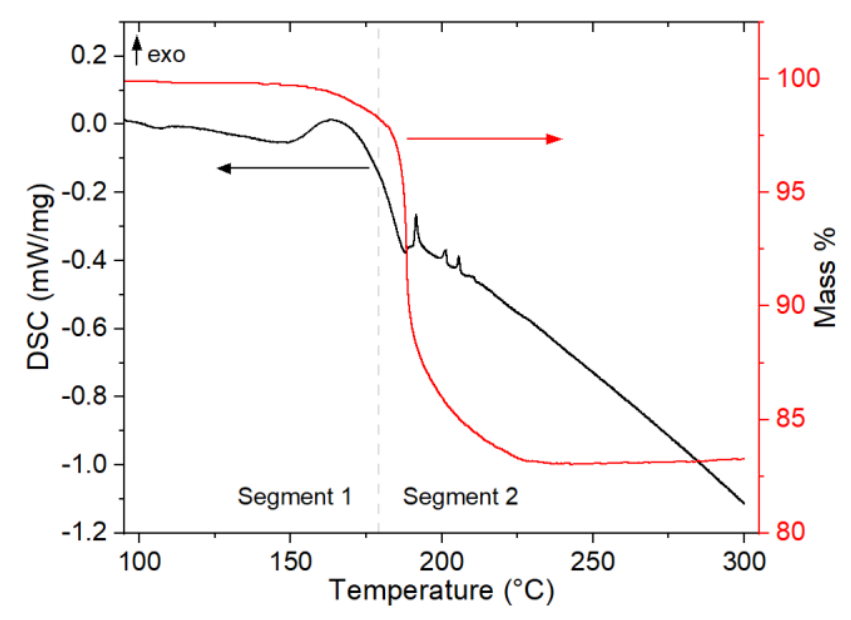

Figure 1: DSC-TGA measurement of a green tape containing 50 vol.\% of HGMS. The two heating segments with weight loss occurring are presented. The organic materials decomposed at $150-225^{\circ} \mathrm{C}$.

According to the FESEM analysis, no delamination of the layers was observed and the silver ink was attaching sufficiently well to the sample surfaces up to 50 vol.\% HGMS content. With higher HGMS content, the mechanical integrity of the sintered samples started to decline. The cross-sections are presented in Figure 2. 


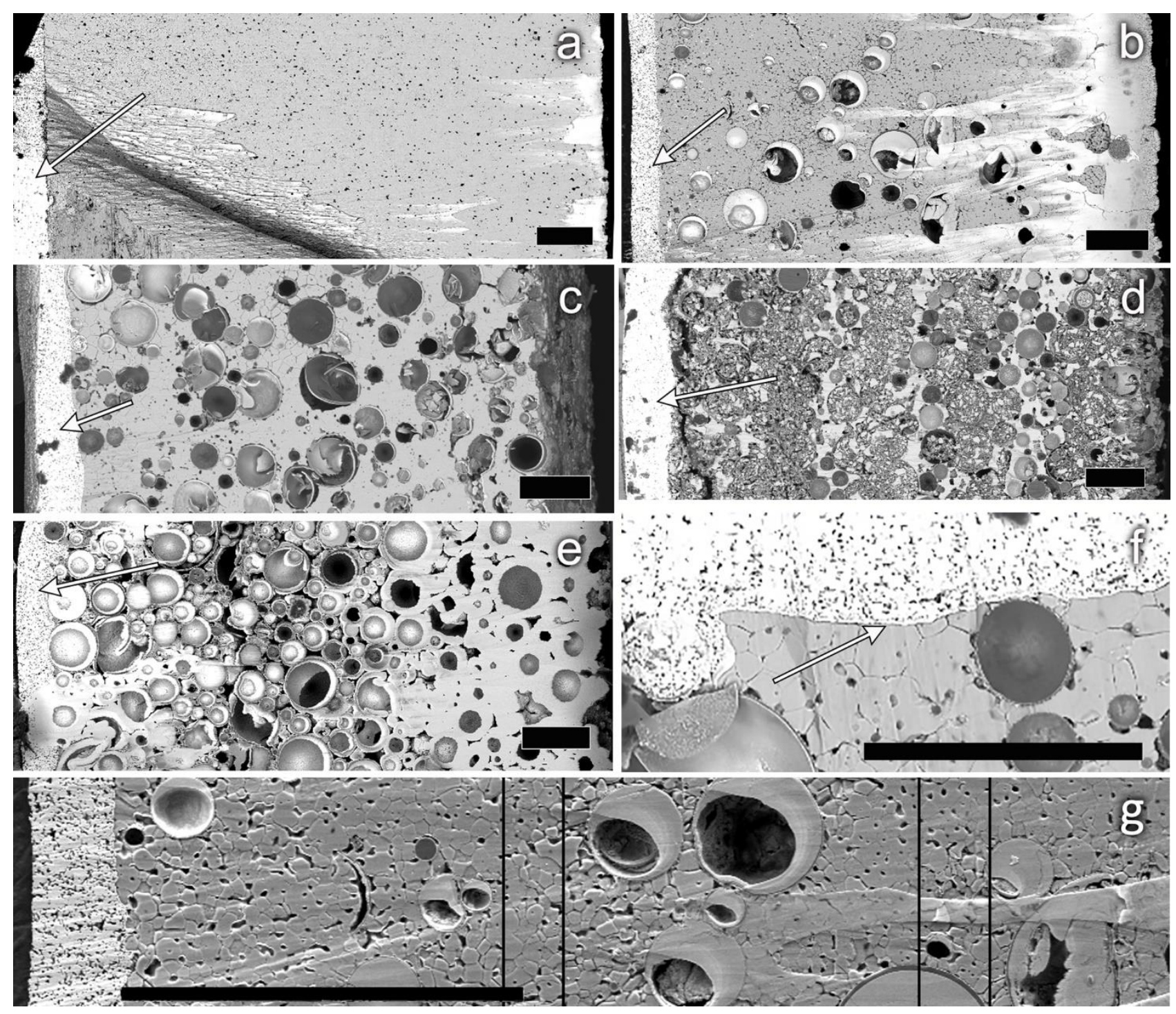

Figure 2. Backscattering images of cross-sections of sintered samples. Silver layer can be seen as a brighter layer on left side of each sample, indicated with an arrow. a: pure LMO, b: 25 vol.\% HGMS, c: 50 vol.\% HGMS, d: 75 vol.\% HGMS, e: 85 vol.\% HGMS, f: Printed silver ink interface with sample containing 50 vol.\% HGMS. g: Magnification of 25 vol.\% HGMS sample with three $200 \mu \mathrm{m}$ thick layers in the image area. Vertical lines indicate the location of estimated layer surfaces, as they were not visible in FESEM inspection. Scale bars on figures a-f: $100 \mu \mathrm{m}, \mathrm{g}: 200 \mu \mathrm{m}$.

The measured dielectric properties, the shrinkages and densities of the tapes are presented in Table 2 . It can be seen that with increasing HGMS content the relative permittivity greatly and continuously decreased at both frequencies while the loss tangent values had the opposite behavior. Supposingly, the level of losses 
could be hindered by selection of a different type of HGMS. The shrinkage of the samples also reduced when the HGMS content was increased as a consequence of the reduced amount of LMO that sinters. The samples were easy to handle until 75 and 85 vol.\% HGMS content, which were rather brittle samples and needed extra care in handling.

Table 2: properties of tapes.

\begin{tabular}{|c|c|c|c|c|c|c|c|c|}
\hline \multirow{2}{*}{ Tape contents } & \multicolumn{2}{|c|}{$5.2 \mathrm{GHz}$} & \multicolumn{2}{|c|}{$10 \mathrm{GHz}$} & \multirow{2}{*}{$\begin{array}{l}\text { Density, } \\
\mathrm{g} / \mathrm{cm}^{3}\end{array}$} & \multirow{2}{*}{$\begin{array}{l}\text { Density, } \\
\% \text { of LMO }\end{array}$} & \multicolumn{2}{|c|}{ Shrinkage } \\
\hline & $\varepsilon r$ & $\tan \delta, E-3$ & $\varepsilon r$ & $\tan \delta, E-3$ & & & $X Y, \%$ & $Z, \%$ \\
\hline $0 \% \mathrm{HGMS}$ & 5.4 & 0.17 & 5.4 & 0.19 & 2.84 & $93 \%$ & $21 \%$ & $21 \%$ \\
\hline $25 \%$ HGMS & 3.5 & 0.60 & 3.5 & 0.65 & 1.77 & $58 \%$ & $13 \%$ & $14 \%$ \\
\hline $50 \%$ HGMS & 2.6 & 1.1 & 2.6 & 1.3 & 1.32 & $43 \%$ & $8 \%$ & $8 \%$ \\
\hline $75 \%$ HGMS & 1.7 & 1.2 & 1.7 & 1.3 & 0.62 & $20 \%$ & $4 \%$ & $3 \%$ \\
\hline $85 \%$ HGMS & 1.4 & 1.4 & 1.5 & 1.7 & 0.39 & $13 \%$ & $4 \%$ & $-4 \%$ \\
\hline
\end{tabular}

The conclusion of the materials' properties is shown in the Table 3 along with some other low permittivity materials. The permittivity of the 50 vol.\% was less than half that of the sintered LMO (5.4). When comparing dielectric properties with other low permittivity microwave materials in the table, the developed composites with 50 vol\%. or more HGMS had the lowest permittivities and still lower loss tangents than all other composites. Polymer - ceramic $\mathrm{C}_{\mathrm{A} M}[10]$ being the only one with a comparable loss tangent, but with a permittivity $44 \%$ higher. Also, the sintering temperature remained the lowest of these materials if the polymer composites and RTF are not considered. This shows the high potential of the developed composite for ULTCC application specific optimization, by tuning the filler content (e.g. 50 to 85 vol.\%) according to the wanted high frequency, (low) permittivity and the tolerable losses. 
Table 3: Microwave properties of low permittivity materials.

\begin{tabular}{|c|c|c|c|c|c|c|c|c|c|}
\hline $\begin{array}{l}\text { Material } \\
\text { type }\end{array}$ & Filler & Load. (\%) & $\begin{array}{l}\text { Fabr. } \\
\text { Temp. } \\
\left({ }^{\circ} \mathrm{C}\right)\end{array}$ & $\begin{array}{l}\text { Meas. freq. } \\
\quad(\mathrm{GHz})\end{array}$ & $\varepsilon_{\mathrm{r}}$ & $\begin{array}{c}\text { Loss tan, } \\
\text { E-3 }\end{array}$ & $\begin{array}{l}\text { Qxf, } \\
\text { E9 }\end{array}$ & $\begin{array}{l}\text { Density } \\
\left(\mathrm{g} / \mathrm{cm}^{3}\right)\end{array}$ & Ref. \\
\hline ceramic & $\mathrm{Li}_{2} \mathrm{MoO}_{4}$ & 100 & 540 & $5.2-10$ & 5.4 & $0.17-0.19$ & - & $2.84(93 \%)$ & $\begin{array}{l}\text { this } \\
\text { study }\end{array}$ \\
\hline $\begin{array}{l}\text { glass - } \\
\text { ceramic }\end{array}$ & HGMS & $\begin{array}{c}85-25 \\
\text { vol. }\end{array}$ & 540 & $5.2-10$ & $1.4-3.5$ & $1.7-0.6$ & - & $\begin{array}{l}0.39-1.77 \\
(13-58 \%)\end{array}$ & $\begin{array}{l}\text { this } \\
\text { study }\end{array}$ \\
\hline $\begin{array}{c}\text { glass - } \\
\text { polymer }\end{array}$ & glass balls & $\begin{array}{c}46.7- \\
18.5 \text { vol. }\end{array}$ & 140 & 0.01 & $2.59-3.0$ & $1.29-1.64$ & - & $\begin{array}{l}0.930-1.1 \\
(73-90 \%)\end{array}$ & 7 \\
\hline $\begin{array}{l}\text { commercial } \\
\text { LTCC }\end{array}$ & - & - & - & 10 & $4.2-19$ & $6-6.6$ & $\begin{array}{l}360- \\
10000\end{array}$ & - & 8 \\
\hline $\begin{array}{l}\text { commercial } \\
\text { LTCC }\end{array}$ & - & - & - & 10 & $4.7-19$ & $1-6$ & $\begin{array}{l}1667- \\
10000\end{array}$ & - & 8 \\
\hline $\begin{array}{l}\text { polymer - } \\
\text { ceramic }{ }_{A G M}\end{array}$ & $\begin{array}{l}\text { PMMA } \\
\text { spheres }\end{array}$ & $30 \mathrm{wt}$. & 500 & $5-10$ & 3.75 & $0.85-1.25$ & - & $1.55(67 \%)$ & 10 \\
\hline $\begin{array}{l}\text { polymer - } \\
\text { ceramic951 }\end{array}$ & $\begin{array}{l}\text { PMMA } \\
\text { spheres }\end{array}$ & $30 \mathrm{wt}$. & 500 & $5-10$ & $6.5-6.5$ & $5.8-6.7$ & - & 2.91 (98\%) & 10 \\
\hline glass- $\mathrm{Al}_{2} \mathrm{O}_{3}$ & graphite & $50 \mathrm{wt}$. & 1250 & 0.002 & 2.8 & - & - & - & 11 \\
\hline $\begin{array}{c}\text { glass- } \\
\text { cordierite }\end{array}$ & graphite & 25 wt. & 1250 & 0.002 & 3.7 & - & - & - & 11 \\
\hline $\begin{array}{l}\text { ceramic - } \\
\text { glass }\end{array}$ & $\mathrm{Al}_{2} \mathrm{O}_{3}$ & $\begin{array}{c}10-15 \\
\text { wt. }\end{array}$ & 640 & 16.64 & $3.9-3.5$ & - & $\begin{array}{c}38000- \\
12500\end{array}$ & $2.87-2.75$ & 14 \\
\hline ceramic & $\mathrm{Li}_{2} \mathrm{MoO}_{4}$ & 100 & $\begin{array}{l}25- \\
120\end{array}$ & 9.60 & $4.6-5.2$ & - & $\begin{array}{c}10200- \\
18500\end{array}$ & $\begin{array}{l}2.6-2.8 \\
(87-93 \%)\end{array}$ & 19 \\
\hline $\begin{array}{l}\text { glass - } \\
\text { ceramic, } \\
\text { LTCC }\end{array}$ & silica & 15 wt. & 650 & 0.001 & 6.4 & 1.00 & - & 3.6 & 26 \\
\hline ceramic & $\mathrm{K}_{2} \mathrm{Mo}_{3} \mathrm{O}_{10}$ & 100 & 520 & - & 5.6 & - & 35830 & - & 27 \\
\hline $\begin{array}{l}\text { glass - } \\
\text { ceramic }\end{array}$ & glass & 50 vol. & $\begin{array}{l}750- \\
950\end{array}$ & $12.4-12.6$ & $6.6-5.8$ & - & 2632 & $2.8-3.0$ & 28 \\
\hline ceramic & $\begin{array}{l}\mathrm{Na}_{2} \mathrm{O}- \\
\mathrm{MoO}_{3}\end{array}$ & 100 & 660 & 13.39 & 4.1 & - & 35000 & 2.98 (92\%) & 29 \\
\hline
\end{tabular}

A simple method to produce low permittivity and low dielectric loss LMO -based ceramic suitable for ULTCC and sinterable at $540{ }^{\circ} \mathrm{C}$ was developed. DSC-TG analysis was utilized to optimize the sintering profile for the tape material especially in the case of high HGMS content ( 50 vol.\% or more). Careful development of manufacturing parameters resulted in green tapes with easy handling and lamination characteristics, with an exceptionally low lamination pressure of $1.25 \mathrm{MPa}$. The low lamination pressure may enable the embedding of delicate discrete components inside the 
laminated structures, which opens up new possibilities for future research. The used silver paste seemed to be suitable for use with the developed LMO -based composition, thus the developed material may be used in ULTCC as expected. The HGMS filler reduced the density of the ULTCC to 13\% (85 vol.\% HGMS) of the pure ULTCC LMO (0 vol.\% HGMS), and it also greatly affected the dielectric properties. The lowest achieved relative permittivity was 1.4 and 1.5 at 5.2 and $10 \mathrm{GHz}$ respectively for the sample containing 85 vol.\% HGMS. The lowest loss tangent values achieved were 1.7 and $1.9 \times 10^{-4}$ at 5.2 and $10 \mathrm{GHz}$ respectively for the sample containing 0 vol.\% HGMS (or sintered LMO) and increased to 1.4 and $1.7 \times 10^{-3}$ respectively with the 85 vol\%. HGMS. The developed material system showed one of the lowest permittivities and losses among a large variety of microwave ceramic and composite materials reported. The dielectric permittivity and losses of the developed materials could be easily adjusted by using different quantities of HGMS.

Author M.N. produced and measured all samples and obtained the used materials. Author T.V. formulated the tape casting slurries and produced the green tapes used in this work. Author T.S. carried out the DSC-TG analysis of the green tape. Authors H.J. and J.J. formulated the hypotheses and discussed the dielectric results of the study. All authors contributed for the writing of the manuscript and evaluation of the results.

The work leading to these results has received funding from the European Research Council (ERC) under the ERC POC grant agreement No. 812837. This work was supported in part by the Academy of Finland 6Genesis Flagship (grant No. 318927), Printed Intelligence Infrastructure (PII) (grant No. 320017) and in part by the European Regional Development Fund project 'Novel digitally fabricated materials for electronics, optics and medical applications (NOVIDAM), grant No. A74080. 
The data that support the findings of this study are available from the corresponding author upon reasonable request.

\section{References}

1. G. F Zhao, T. Ishizaka, H. Kasai, M. Hasegawa, T. Furukawa, H. Nakanishi, H. Oikawa. Ultralow-dielectricconstant films prepared from hollow polyimide nanoparticles possessing controllable core sizes. Chem. Mater. 21, 419-424 (2009). doi: 10.1021/cm802989u

2. M. Nelo, H. Liimatainen, M. Väätäjä, J. Ukkola, J. Juuti, H. Jantunen. Solid air - Low temperature manufacturing of ultra-low permittivity composite materials for future telecommunication systems. Front. Mater. 4, (2019). doi: 10.3389/fmats.2019.00094

3. B. Zhao, C. Zhao, C. Wang and C. B. Park. Poly(vinylidene fluoride) foams: a promising low-k dielectric and heat-insulating material. J. Mater. Chem. C, 6, 3065-3073 (2018). doi: 10.1039/c8tc00547h

4. W. C. Wang, R. H. Vora, E. T. Kang, K. G. Neoh, C. K. Ong, L. F. Chen. Nanoporous ultra-low-k films prepared from fluorinated polyimide with grafted poly(acrylic acid) side chains. Adv. Mater. 16, 54-57 (2004). doi: 10.1002/adma.200305185

5. L. N. Chellis, R. M. Japp, W. J. Summa, W. J. Rudik, D. W. Wang. Flame retardant, low dielectric constant microsphere filled laminate. Patent US5126192A

6. D. Kellerman. Micro-electronics devices and methods of manufacturing same. Patent US4781968A

7. J. Chen, D. Meng, Y. Feng, N. Li, A. Krivda, F. Greuter, J. Rocks. Epoxy composites with glass bubbles for electrical application, 2013 Electrical Insulation Conference. 20-24 (2013). doi: 10.1109/EIC.2013.6554194

8. M. T. Sebastian, H. Jantunen. Low loss dielectric materials for LTCC applications: a review.

Int. Mater. Rev., 53, 57-90 (2008) DOI: 10.1179/174328008X277524

9. J. Zhou. Towards rational design of low-temperature co-fired ceramic (LTCC) materials. J. Adv. Ceram., 1, 89-99 (2012). doi: 10.1007/s40145-012-0011-3

10. M. Sobocinski, M. Teirikangas, J. Peräntie, T. Vahera, M. Nelo, J. Juuti, H. Jantunen. Decreasing the relative permittivity of LTCC by porosification with poly(methyl methacrylate) microspheres. Ceram. Int. 41, 1087110877 (2015). doi: 10.1016/j.ceramint.2015.05.028

11. B. Synkiewicz, D. Szwagierczak, J. Kulawik. Multilayer LTCC structures based on glass-cordierite layers with different porosity. Microelectron. Int., 34, 110-115 (2017). doi: 10.1108/MI-12-2016-0084 
12. A. Bittner, U. Schmid. Permittivity of LTCC Substrates Porousified With a Wet Chemical Etching Process. Procedia Engineering, 5, 327-330 (2010). doi:10.1016/j.proeng.2010.09.114

13. R. K. Nishihora, P. L. Rachadel, M. G. Novy, Q. D. Hotza. Manufacturing porous ceramic materials by tape casting-A review. J. Eur. Ceram. Soc., 38, 988-1001 (2018). doi: 10.1016/j.jeurceramsoc.2017.11.047

14. J. Xi, G. Chen, F. Liu, F. Shang, J. Xu, C. Zhou, C. Yuan. Synthesis, microstructure and characterization of ultra-low permittivity CuO-ZnO-B2O3-Li2O glass/Al2O3 composites for ULTCC application. Ceram. Int., 45, , 24431-24436 (2019). doi: 10.1016/j.ceramint.2019.08.166

15. M. T. Sebastian, H. Wang, H. Jantunen. Low temperature co-fired ceramics with ultra-low sintering temperature: A review. Curr. Opin. Solid State Mat. Sci., 20, 151-170 (2016). doi: 10.1016/j.cossms.2016.02.004

16. J. Varghese, T. Siponkoski, M. Sobocinski, T. Vahera, H. Jantunen. Multilayer Functional Tapes Cofired at 450 degrees C: Beyond HTCC and LTCC Technologies. ACS Appl. Mater. Interfaces, 10, 11048-11055 (2018). doi: 10.1021/acsami.8b00978

17. S.-Z. Hao, D. Zhou, F. Hussain, W.-F. Liu, J.-Z. Su, D.-W. Wang, Q.-P. Wang, Z.-M. Qi, C. Singh, S. Trukhanov. Structure, spectral analysis and microwave dielectric properties of novel $x(\mathrm{NaBi}) 0.5 \mathrm{MoO} 4-(1-\mathrm{x}) \mathrm{Bi} 2 / 3 \mathrm{MoO} 4(\mathrm{x}$ $=0.2-0.8$ ) ceramics with low sintering temperatures. J. Eur. Ceram. Soc. 40, 3569-3576 (2020). Doi: 10.1016/j.jeurceramsoc.2020.03.074.

18. H.-H. Guo, D. Zhou, C. Du, P.-J. Wang, W.-F. Liu, L.-X. Pang, Q.-P. Wang, J.-Z. Su, C. Singh, S. Trukhanov. Temperature stable Li2Ti0.75(Mg1/3Nb2/3)0.2503-based microwave dielectric ceramics with low sintering temperature and ultra-low dielectric loss for dielectric resonator antenna applications. J. Mater. Chem. C 8 (2020) 4690-4700. Doi: 10.1039/D0TC00326C.

19. H. Kähäri, M. Teirikangas, J. Juuti, H. Jantunen. Dielectric Properties of Lithium Molybdate Ceramic Fabricated at Room Temperature. J. Am. Ceram. Soc. 97, 3378-3379 (2014). doi: 10.1111/jace.13277

20. H. Kähäri, M. Teirikangas, J. Juuti, H. Jantunen. Improvements and Modifications to Room-Temperature Fabrication Method for Dielectric Li2MoO4 Ceramics. J. Am. Ceram. Soc. 98, 687-689 (2017). doi: 10.1111/jace.13471

21. M. Väätäjä, H. Kähäri, J. Juuti, H. Jantunen. Li2MoO4 -Based Composite Ceramics Fabricated from Temperature- and Atmosphere-Sensitive MnZn Ferrite at Room Temperature. J. Am. Ceram. Soc. 100, 36263635 (2017). doi: 10.1111/jace.14914 
22. D. Zhou, C. A. Randall, H. Wang, L.-X. Pang, and X. Yao. "Microwave Dielectric Ceramics in Li2O-Bi2O3MoO3 System with Ultra-Low Sintering Temperatures," J. Am. Ceram. Soc., 93, 1096-100 (2010). doi: $10.1111 / \mathrm{j} .1551-2916.2009 .03526 . x$

23. S. Kumakura, Y. Shirao, K. Kubota, S. Komaba. Preparation and electrochemical properties of Li2MoO3/C composites for rechargeable Li-ion batteries. Phys. Chem. Chem. Phys., 18, 28556-28563 (2016). Doi: 10.1039/C6CP05162F

24. I.Z. Zhumatayeva, I.E. Kenzhina, A.L. Kozlovskiy, M.V. Zdorovets. "The study of the prospects for the use of Li0.15Sr0.85TiO3 ceramics", J. Mater. Sci.: Mater. Electron. 31, 6764-6772 (2020). Doi: 10.1007/s10854020-03234-9

25. N. Joseph, J. Varghese, M. Teirikangas, T. Vahera, H. Jantunen. Ultra-Low-Temperature Cofired Ceramic Substrates with Low Residual Carbon for Next-Generation Microwave Applications. ACS Appl. Mater. Interfaces, 11, 23798-23807 (2019). doi: 10.1021/acsami.9b07272

26. H. Yu, K. Ju, J. Liu, Y. Li. Tape casting and dielectric properties of SiO2-filled glass composite ceramic with an ultra-low sintering temperature. J Mater Sci: Mater Electron, 25, 5114-5118 (2014). doi: $10.1007 / \mathrm{s} 10854-014-2280-9$

27. G.-q. Zhang, J. Guo, L. He, D. Zhou, H. Wang, J. Koruza, M. Kosec. Preparation and Microwave Dielectric Properties of Ultra-low Temperature Sintering Ceramics in K2O-MoO3 Binary System. J. Am. Ceram. Soc., 97, 241-245 (2014). doi: 10.1111/jace.12646

28. S.-O. Yoon, S.-H. Shim, K.-S. Kim, J-G. Park, S. Kim. Low-temperature preparation and microwave dielectric properties of ZBS glass-Al2O3 composites, Ceram. Int., 35, 1271-1275 (2009). doi: 10.1016/j.ceramint.2008.04.003

29. G.-q. Zhang, H. Wang, J. Guo, L. He, D.-d. Wei, Q.-b. Yuan. Ultra-low Sintering Temperature Microwave Dielectric Ceramics Based on Na2O-MoO3 Binary System. J. Am. Ceram. Soc., 98 528533 (2015). doi: 10.1111/jace.13297 